\title{
O DIREITO DE AUTONOMIA: GÊNERO E JUSTIÇA SOCIAL EM SOCIEDADES DEMOCRÁTICAS
}

Jaime Santos Júnior ${ }^{18}$

\section{THE RIGHT OF AUTONOMY: GENDER AND SOCIAL JUSTICE IN DEMOCRATIC SOCIETIES.}

\section{Resumo}

A emergência de demandas oriundas de diferentes movimentos sociais nas últimas décadas ensejou uma re exão no interior das ciências sociais acerca da forma como tais demandas poderiam ser equacionadas. Isto porque o conteúdo universalista dos princípios republicanos é confrontado com o pluralismo de valores de onde emanam as reivindicações de tais movimentos. É neste contexto que são formuladas políticas especí cas para a promoção da autonomia das mulheres; uma delas é o ingresso no mercado de trabalho. Se a relação entre acesso a um emprego e autonomia feminina nem sempre é clara, mobilizamos nesse texto o argumento rawlsiano de justiça social como um recurso analítico fecundo para se pensar como tais demandas podem ser agenciadas em sociedades democráticas.

Palavras-chave: Trabalho. Justiça social. Autonomia.

\section{Abstract}

The emergence of demands from different social movements in recent decades, elicited a re ection within the social sciences about how such claims could be set out. The universalistic content of republican principles 
is faced with the plurality of values which emanate from the claims of such movements. This is the ground where speci c policies are formulated to promote women's autonomy; one of them is the entry into the labor market.

If the relation between employment and female autonomy is far from been clear, we mobilize in this article the Rawlsian argument for social justice as a fertile analytical resource to thinking about how such claims may be deal with in democratic societies.

Keywords: Employment. Social justice. Autonomy.

\section{Apresentação}

Ainda que por diferentes caminhos, o tema "trabalho" sempre esteve presente nas análises de gênero. Não por ser o único lugar onde as assimetrias entre os sexos se revelavam, mas sobretudo por conter, ainda que em potencial, possibilidades emancipatórias ligadas ao acesso à renda. Neste veio, estudos clássicos revelaram que a inserção da categoria gênero nas análises sobre relações de trabalho não poderia ser desprezada, sob pena de homogeneizar formas de exploração que ganhava contornos especiais através de outras clivagens. É assim que gênero, geração, proveniência, etnia, entre outros, suplantaram binaridades clássicas nas análises sobre trabalho tais como: capitalistas e operários, ricos e pobres, exploradores e explorados etc. A introdução daquelas variáveis contribuíram para arejar o debate no interior das ciências sociais.

Por seu turno, a amplitude das interpretações dadas ao trabalho e a sua importância como elemento de integração social não foram poucas, ainda que para rejeitá-lo ou para a rmá-lo. Acompanharam tais interpretações estudiosos dos mais diferentes matizes do conhecimento como lósofos, economistas e sociólogos. Não é nosso objetivo neste artigo inventariar esta pluralidade de concepções. Interessa-nos, aqui, analisar a relação entre a reivindicação por autonomia das mulheres e sua associação com a inserção no mercado de trabalho. A hipótese que desenvolvemos diz respeito às pos- 
sibilidades de assentar as demandas oriundas da questão de gênero - enquanto movimento social - em termos de justiça social, não se restringindo a integração via trabalho.

O ingresso das mulheres no mercado de trabalho ainda é uma bandeira de luta do movimento feminista. Visto como um elemento potencializador de sua autonomia, o trabalho poderia ajudar a construir uma representação sobre as mulheres em busca da superação das desigualdades que marcam a sua participação no mercado de trabalho. As análises sobre a divisão sexual do trabalho evidenciam assimetrias entre os sexos, inerentes ao próprio mercado de trabalho e à esfera reprodutiva, tornando assim inteligível que as formas de exploração não se manifestam igualmente para homens e muIheres. No interior da sociologia do trabalho viu-se que a variável gênero não poderia ser desprezada como, de certa forma, zera a sociologia clássica a esse respeito. Uma vasta literatura foi produzida para tratar da temática das relações sociais entre os sexos (BOURDIEU, 2002; GOFFMAN, 1977; SCOTT, 1990;) que fez desenvolver, por sua vez, correntes epistemológicas que trouxeram grandes contribuições para a pesquisa social ${ }^{19}$.

Entretanto, não foi por acaso que o trabalho se constituiu como elemento principal para se pensar a autonomia dos indivíduos e meio de integração social. A constituição de uma sociedade industrial pôs como elemento central o trabalho assalariado, protegido e em tempo integral. Neste arranjo, que tinha ainda a participação dos regimes de Welfare como garantidor de serviços públicos para a população, presenciamos o desenvolvimento das economias dos países capitalistas centrais. Além disso, a manutenção de baixos índices de desemprego - sendo este caracterizado como conjuntural - fez avançar as políticas empregatícias nesses países (HARVEY, 1993). Este período, conhecido como "os trinta gloriosos", atraiu a atenção da sociologia com o desenvolvimento da sociologia das relações industriais (PIORE; SABEL, 1984), da sociologia do trabalho, que tomavam o "trabalho" e a "classe" como categorias analíticas importantes; por conseguinte, o espaço fabril constituía um lócus privilegiado de observação e análise da sociedade.

No pós 1970 - ainda tomando como referência uma narrativa euro- 
cêntrica - em meio ao contexto de retração do emprego e ampliação das formas de desemprego, aquela visão produtivista da sociedade é tentada a ceder espaço para outras formas de abordagens na qual o trabalho - e seus correlatos: sindicalismo, políticas empregatícias, classe etc. - concorre com outras demandas por emancipação. Assim, as análises sobre globalização e os estudos sobre comparações internacionais permitiram oxigenar o de bate a respeito das heterogeneidades presentes nas relações sociais entre os sexos, ensejando diferentes demandas, em diferentes contextos. Para Talahite (2010), quando os efeitos da globalização começaram a ser estudados depois de 1980, com a elaboração de novos indicadores de gênero, as grandes agências mundiais de desenvolvimento, a exemplo do BancoMundial, Programa das Nações Unidas para o Desenvolvimento (PNUD) e Organização para a Cooperação e Desenvolvimento Econômico (OCD), elencaram como meta a participação econômica das mulheres com o acesso a um emprego remunerado como um índice de autonomia. Ao colocar em questão a relação entre a participação das mulheres no mercado de trabaIho e sua autonomia, Talahite (2010) constata que o acesso das mulheres ao mercado de trabalho não signi ca melhoria na qualidade dos empregos. Para ela, quando se usa como indicador a taxa de participação das mulheres na população ativa, por englobar todas as formas de emprego, não é possível medir o grau de autonomia das mulheres, mas a e cácia da utilização da mão de obra feminina. Acontece que a taxa de participação da mão de obra feminina varia de um país para outro a depender de características da população, tais como nível de instrução, índice de fecundidade etc.

Os estudos que trabalham com as comparações internacionais também evidenciam que a estrutura dos mercados de trabalho difere de um país para outro, a exemplo dos sistemas de proteção ao desemprego, das instâncias de acesso ao emprego, da organização interna das empresas, além de características culturais da população ativa (COSTA et al., 2008; GUIMARÃES et al., 2008; SASSEN, 2010). Estes resultados nos permitem a rmar que, embora o processo de reestruturação produtiva que teve início na década de 1970 nos países desenvolvidos tenha ocasionado um movimento de reorganização dos mercados de trabalho, com destaque para a 
ampliação de formas precárias de trabalho - conquanto reconhecendo essa tendência -, não se pretende arguir que estejamos diante de uma convergência irresistível em direção a um padrão único, seja no que concerne às formas de inserção ocupacional, seja no que concerne às situações de desemprego. Longe disso; sabemos que cada contexto social experimenta e reage de maneira particular às mudanças na economia internacional. Nesse sentido, podem ter lugar tanto a emergência de novas con gurações nas relações de emprego, quanto a permanência de formas precárias de emprego, ou mesmo o ressurgimento de formas pretéritas de trabalho, inclusive em situações- -limite como as do trabalho em situações análogas à da escravidão (BALES, 2004), ou do trabalho infantil, apenas para tomarmos dois exemplos.

Ora, se nos países capitalistas centrais as políticas de inserção ocupacional assumiram lugar de destaque na agenda dos governos no período dos "trinta gloriosos", estando sob fogo cruzado com as mudanças na economia e a inserção das políticas "neoliberais", o Brasil não esteve imune a este processo. De maneira sucinta, cabe destacar que não tivemos sequer a consolidação de um padrão ocupacional em que o emprego assalariado, protegido e de longa duração tenha coberto vasta população da mão de obra empregada. Aqui predominaram formas erráticas de trajetória ocupacional, ao arrepio das leis trabalhistas e com fraca e restrita participação do Estado para os períodos de desemprego, ou como ofertante de serviços sociais nos moldes dos regimes de welfare. É neste contexto, já "precário", que as políticas liberalizantes são implementadas. Sobre as consequências, não nos iremos ater aqui a elas em virtude da necessidade de atenção privilegiada a este aspecto; interessa-nos, pois - alinhavando novamente ao nosso argumento -, destacar que as políticas de emprego e de inserção ocupacional sempre estiveram presentes na pauta dos governos e dos sindicatos pela própria pressão que os movimentos feministas exerceram.

Dessa forma, está claro que: a) ao se falar em trabalho, na verdade estamos falando em diferentes contextos sociais em que este se realiza. Por conseguinte, as representações sobre o mesmo nem sempre são as mesmas; b) não apenas agências internacionais como o Banco Mundial, 
PNUD e OCDE, elegeram como meta a participação econômica das muIheres com o acesso a um emprego remunerado como um índice de autonomia; tal medida também permeia a pauta de governos em diferentes países e constitui bandeira de luta de movimentos sociais feministas. Dito isto, a hipótese que desenvolvemos sustenta um pretenso deslocamento da questão da autonomia das mulheres, retirando-a do campo da inserção ocupacional e pondo-a como uma questão de justiça. O contexto em que esse argumento é desenvolvido tem a ver com o momento peculiar das sociedades democráticas modernas, talvez melhor expresso em forma de um dilema. Como equacionar a pluralidade de reivindicações que emanam dos mais diferentes setores da sociedade - entre elas as reivindicações pela autonomia das mulheres - e a coesão simbólica que deu fundamento à ideia de Estado-nação moderno? Nosso próximo passo será discutir esses pontos supramencionados com vistas a avançar neste debate ou, ao menos, situar melhor os seus desdobramentos.

\section{O lugar do trabalho na questão da autonomia}

O atual cenário no que se refere aos mercados de trabalho desa a, em sua complexidade, o entendimento das mudanças ora em curso em realidades socioeconômicas particulares. As consequências da reestruturação produtiva nem sempre são claras no sentido de que ela tenha operado um processo de precarização e degradação das condições de trabalho, conquanto boa parte da literatura sublinhe o argumento de que o aumento da exibilidade e a presença de altos índices de desemprego têm permitido um maior controle sobre a parcela da força de trabalho ocupada. Efeitos desse processo são perceptíveis até mesmo quando se observa o grupo formado por aqueles que possuem a quali cação exigida pelo mercado mas que, ainda assim, não encontraram emprego (EHRENREICH, 2006). Não sem razão já se vaticinou que "a acumulação exível parece implicar níveis relativamente altos de desemprego estrutural, rápida destruição e reconstrução de habilidades, ganhos modestos de salários reais e o retrocesso do poder sindical" (HARVEY, 1993, p. 141). 
Entretanto, e atestando a complexidade do processo e a ausência de cursos unívocos, crescente literatura tem documentado, no caso especí co do Brasil dos anos recentes, o aumento da formalização e da intensi cação do trabalho, um e outro exprimindo-se sob diversas formas (DAL ROSSO, 2008; DEDECCA, 1999; GUIMARAES, 2009; POCHMANN, 1999; RAMOS 2009), e com con gurações distintas nos setores de atividade.

Especialmente em mercados de trabalho como o brasileiro, com um desenho institucional precário no que se refere a seguros assistenciais (POCHMANN, 2008; GUIMARÃES, 2004), tais transformações acabam por expor uma fração da força de trabalho à vivência de uma extrema vulnerabilidade na relação com o trabalho e tem sido destacável a literatura que tem se voltado para tratar da experiência subjetiva do trabalho, nessas condições (AGIER; CASTRO; GUIMARÃES, 1995; CARDOSO, 2000; DAU; CONCEIÇÃO; RODRIGUES, 2009; GUIMARÃES, 1998; LEITE; GITAHY, 2005; LIMA, 2007; RAMALHO; SANTANA, 2003)

$\mathrm{Na}$ esteira dessas mudanças, há uma pluralidade de interpretações acerca dessa nova morfologia do trabalho e do lugar que ele ocupa enquanto elemento propiciador de uma suposta autonomia - para o nosso caso, a autonomia das mulheres -. Percorrendo a literatura sociológica, duas principais vertentes interpretativas se destacam ${ }^{20}$. A primeira refere-se a estudos que advogam que o trabalho teria deixado de ser uma categoria analiticamente importante por ter perdido espaço para outras esferas da vida social, como o lazer. Surgem, então, os diversos argumentos em torno de um pretenso "adeus ao trabalho", como os de Gorz (1982), Habermas (1987), Offe (1989), Schaff (1990), Lojkine (1995), Lazzarato e Negri (2001), De Masi (2003).

Para esse grupo de autores, mutatis mutandis, a reestruturação produtiva, a automação e a intelectualização dos processos de trabalho teriam aberto as possibilidades de superação da contradição básica do sistema capitalista, a subsunção do trabalho pelo capital (LESSA, 2007). Isso ocorreria na medida que as fronteiras entre o trabalho manual e o intelectual 
teriam desaparecido e, neste sentido, desenvolver-se-ia, nos interstícios do capitalismo, a "intelectualidade de massa", um novo sujeito, social e politicamente hegemônico (LAZARATTO; NEGRI, 2001). Já para Schaff (1990), a nova revolução técnico-industrial permitiria a superação do trabalho manual; nessas condições, às pessoas não restaria outra solução senão a de encontrarem outras atividades que dessem sentido às suas vidas, a exemplo de hobbies, turismo etc. Mesma tese de De Masi (2003), que vê na automação a possibilidade da "libertação do trabalho". Para ele, a sociedade pós-industrial em que estamos vivendo inauguraria uma condição mais intelectualizada de vida, "[...] deslocando a exploração dos braços, para o cérebro, cujas características valoriza e do qual está pronta a reproduzir alguns mecanismos através da inteligência arti cial" (DE MASI, 2003, p. 69).

Nesse mesmo sentido vai o argumento de Lojkine, na obra "A Revolução Informacional" (1995). Nela, Lojkine postula que o caráter imaterial da informação fez dela uma mercadoria impossível. Nesse sentido, o produto do trabalho não seria mais um objeto material, mas uma informação, ou seja, algo imaterial. A objetivação não é mais a transformação da matéria, mas uma atividade realizada pela máquina (LESSA, 2007).

Os homens estariam, então, livres para desenvolver suas potencialidades. As teses de Rifkin (2004) também exploram essa ideia, de que a redução brutal do número de empregos, levada a cabo pela tecnologia, obrigar-nos-ia a encontrar outras formas de sociabilidade.

Ao $m$ e ao cabo, os autores que se encaixam nessa perspectiva analítica vão além de propor a hipótese da mera ressigni cação do trabalho. A redução drástica do número de trabalhadores fabris, ocorrida nos últimos vinte anos, ao lado da ascensão de empregos na área de serviços e da elevação dos requerimentos de quali cação, e consequente valorização do componente intelectual associado aos processos de trabalho, estariam no cerne das discussões sobre a viabilidade analítica da categoria trabalho.

Colocando-a como um elemento em vias de extinção, ou interpretando-a como possibilidade de superação daquela que fora tida como a contradição básica do sistema capitalista (a que antepunha trabalho e capital e, assim, forjava uma relação elementar de alteridade que organizava o cerne 
dos con itos e chances de mudança), esses autores esquecem-se, muitas vezes, de perceber continuidades, ainda que transmutadas, nas transformações manifestadas pelas relações de trabalho nos dias de hoje.

Além disso, tais autores não estão no veio analítico que discute o potencial emancipatório do trabalho para as mulheres. Em suas análises, estão sempre tomando como referência o trabalho masculino, formal e em tempo integral. Ao fazer "vista grossa" para as peculiaridades da participação das mulheres no mercado de trabalho, tais estudos omitem por completo processos que indicam muitas vezes a precarização do trabalho, a exemplo da feminização de setores de atividade (SEGNINI, 1998), postos de trabalho precários preenchidos eminentemente por mulheres, formas especí cas de inserção e usos da mão de obra feminina assentados em atributos supostamente femininos etc. Já bastante explorados pela literatura que trata da questão de gênero e trabalho (GUIMARAES, 2009; MOLINIER, 2008; TEIGER; DANIELLOU, 1988; ). Deve-se ainda destacar que aqueles estudos viram na redução do número de trabalhadores fabris e no aumento do componente intelectual nos processos de trabalho, o que para eles seria uma tendência a se alastrar por outros setores de atividade. No entanto, novas formas de usos da mão de obra, o retorno de relações precárias de trabalho e a permanência de formas de organização intra-empresa - que nada deixam a desejar do que poderia se caracterizar como "fordista" -, passaram ao largo dessas análises.

$O$ véu que encobria aquelas análises que vaticinavam o " $m$ do trabaIho", supondo a emergência de uma sociedade pós-industrial (BELL, 1977), não só abria espaço para uma discussão sobre a composição da classe operária ${ }^{21}$ como se movimentava na elaboração de um arcabouço teórico capaz de dar conta da manifestação dos con itos na sociedade pós -industrial. Talvez em virtude da sua abrangência, tais estudos se mostraram pouco e cientes em face dos estudos de caso. As leituras feitas em diferentes países, com relação aos seus mercados de trabalho, apontam que as possibilidades de tendência unívoca na manifestação de fenômenos como o desemprego de longa duração não são idênticas em diferen- 
tes contextos. Ao invés, tais estudos reforçam a tese de que mercados de trabalho amparados por diferentes arranjos institucionais, per $s$ de mão de obra e em diferentes conjunturas político-econômicas, revelam características particulares muitas vezes especí cas a determinados contextos. Um bom exemplo pode ser o caso brasileiro: aqui, ao contrário do movimento que se veri cou após 1970 nos países capitalistas avançados, o mercado de trabalho tem demonstrado crescimento da formalização dos empregos (superando o limiar de 50\% da força de trabalho empregada em 2010, fato inédito). Além disso, outra característica peculiar do nosso mercado de trabalho, no que tange à trajetória ocupacional, demonstra um per I errático de entrada e saída do mercado formal de trabalho. No nosso caso, a carteira de trabalho "assinada" assumiu uma importante referência nos marcos demarcatórios da cidadania no Brasil e no imaginário coletivo dos trabalhadores. Com isto, ainda que seja possível arguir no sentido do aumento do desemprego estrutural, como o fazem Antunes (1999), Alves (2000), Beck (2000), Castel (1998), Lessa (2007), entre outros, a manifestação de fenômenos como este ganha contornos especiais em diferentes países (POCHMANN, 2001; GUIMARÃES et. al., 2008). Além do mais, quando Gorz (1982) estava falando em "adeus ao proletariado" e Habermas (1975) desenvolvendo o argumento da dissipação dos con itos no seio da sociedade, vivíamos um período de efervescência dos trabalhadores, com forte atuação dos sindicatos (ABRAMO, 2000).

No entanto, se é digno de nota que manifestações de tendência unívoca rumo à perda de referência do trabalho encontram resistência quanto a sua generalização, não se pode negar a emergência de novas demandas por parte dos movimentos sociais, que posicionam seus interesses para além do exclusivismo do "trabalho" enquanto lócus privilegiado de superação dos con itos na sociedade capitalista. Assim sendo - e pedimos ao leitor que retenha este argumento -, ainda que a inserção pelo trabalho não possaser afastada enquanto elemento de autonomia para as mulheres, principalmente pelo acesso à renda oriunda deste, a sua autonomia, no sentido que iremos desenvolver aqui, deve ser posta na forma de direitos, deslocando a questão da "inserção pelo trabalho" para uma questão de justiça social. 
Avançando no argumento anteriormente exposto, não se trata de a rmar que os estudos sobre as relações de trabalho onde o gênero aparece como um elemento revelador de discriminações devam ser desprezados. Longe disto, argumentamos que a questão da autonomia das mulheres deve ser pensada na forma de justiça social, e não como mera inserção no mercado de trabalho.

O primeiro argumento a favor do que estamos arguindo começa pela própria fraqueza do vínculo entre autonomia das mulheres e trabalho. Assim pensado, argumenta Talahite (2010), os indicadores de gênero possuem apenas um conteúdo normativo, prioriza-se a elevação do indicador como medida de autonomia em detrimento da sua diferenciação interna. Além disso, quando relacionada com outros fatores, a taxa de participação das mulheres no mercado de trabalho revela serem elas uma classe minoritária. Para Talahite (2010), nem sempre o acesso a um emprego remunerado para as mulheres está ligado à melhoria na qualidade do emprego e as condições de trabalho muitas vezes não Ihes permitem ascender à autonomia desejada.

No caso brasileiro ${ }^{22}$, tomando-se o período de 1976 a 1997 como ilustra a Tabela 1, é possível evidenciar um crescimento de 30 milhões de trabaIhadoras na população economicamente ativa (PEA), porém, há que se ressaltar que tal crescimento não se veri cou com relação à participação das mulheres no conjunto dos empregados, no qual os homens representam mais de $60 \%$. O que reforça achados como os de Talahite (2010), Segnini (1998), Huws (2004), entre outros, ao mostrar que a diferenciação interna do dado bruto - representada aqui pelo trabalho informal, atividades não remuneradas e informais - contraria a simples associação entre trabalho e autonomia das mulheres.

22 Valemo-nos aqui de um banco de informações sobre o trabalho das mulheres no Brasil produzido por Cristina Bruschini e Miriam Bizzochi, de posse da Fundação Carlos Chagas (FCC). Disponível em: http:// www.fcc.org.br/bdmulheres/index.php?area=home 
Tabela 1 - Mulheres e homens no mercado de trabalho:

Indicadores de participação econômica

Brasil - 1976 a 2007

\begin{tabular}{|c|c|c|c|c|c|c|}
\hline \multirow[b]{3}{*}{ Anos } & \multicolumn{4}{|c|}{ Mulheres } & & \\
\hline & \multicolumn{3}{|c|}{ PEA } & \multirow{2}{*}{\begin{tabular}{|l} 
Ocupadas \\
(Milhões)
\end{tabular}} & \multicolumn{2}{|c|}{ Empregadas } \\
\hline & (Milhões) & $\begin{array}{c}\text { Taxa de } \\
\text { atividade }\end{array}$ & $\begin{array}{l}\text { Porcentagem de } \\
\text { mulheres na PEA }\end{array}$ & & (Milhões) & $\begin{array}{c}\text { Porcentagem } \\
\text { de mulheres } \\
\text { entre os em- } \\
\text { pregados }\end{array}$ \\
\hline 1976 & 11,4 & 28,8 & 28,8 & 11,2 & 7,3 & 30,3 \\
\hline 1981 & 14,8 & 32,9 & 31,3 & 14,1 & 9,4 & 32,2 \\
\hline 1983 & 16,8 & 35,6 & 33,0 & 16,0 & 10,5 & 33,4 \\
\hline 1985 & 18,4 & 36,9 & 33,5 & 17,8 & 11,8 & 34,4 \\
\hline 1990 & 22,9 & 39,2 & 35,5 & 22,1 & 14,7 & 36,7 \\
\hline 1993 & 28 & 47 & 39,6 & 25,9 & 11,1 & 31,8 \\
\hline 1995 & 30 & 48,1 & 40,4 & 27,8 & 11,6 & 32,6 \\
\hline 1997 & 30,4 & 47,2 & 40,4 & 27,3 & 11,9 & 33,1 \\
\hline 1998 & 31,3 & 47,5 & 40,7 & 27,6 & 12,5 & 33,9 \\
\hline 2002 & 36,5 & 50,3 & 42,5 & 32,3 & 15,2 & 35,8 \\
\hline 2007 & 43.091 .498 & 52,4 & 43,6 & 38.422 .820 & 19.521 .257 & 37,5 \\
\hline
\end{tabular}

\begin{tabular}{|c|c|c|c|c|c|c|}
\hline \multirow[b]{3}{*}{ Anos } & \multicolumn{4}{|c|}{ Homens } & & \\
\hline & \multicolumn{3}{|c|}{ PEA } & \multirow{2}{*}{$\begin{array}{l}\text { Ocupados } \\
\text { (Milhões) }\end{array}$} & \multicolumn{2}{|c|}{ Empregados } \\
\hline & (Milhões) & $\begin{array}{c}\text { Taxa de } \\
\text { atividade }\end{array}$ & $\begin{array}{c}\text { Porcentagem } \\
\text { de homens na } \\
\text { PEA }\end{array}$ & & (Milhões) & $\begin{array}{c}\text { Porcentagem } \\
\text { de homens } \\
\text { entre os em- } \\
\text { pregados }\end{array}$ \\
\hline 1976 & 28,2 & 73,6 & 71,2 & 27,8 & 16,7 & 69,7 \\
\hline 1981 & 32,6 & 74,6 & 68,7 & 31,2 & 19,8 & 67,8 \\
\hline 1983 & 34,6 & 74,8 & 67,0 & 32,4 & 21,0 & 66,6 \\
\hline 1985 & 36,6 & 76 & 66,5 & 35,4 & 22,5 & 65,2 \\
\hline 1990 & 41,6 & 75,3 & 64,5 & 40 & 25,4 & 63,3 \\
\hline 1993 & 42,8 & 76 & 60,4 & 40,5 & 23,8 & 68,2 \\
\hline 1995 & 44,2 & 75,3 & 59,6 & 41,9 & 24 & 67,4 \\
\hline 1997 & 44,8 & 73,9 & 59,6 & 41,9 & 24,2 & 66,8 \\
\hline 1998 & 45,6 & 73,6 & 59,3 & 42,3 & 24,2 & 66,1 \\
\hline 2002 & 49,5 & 73,2 & 57,6 & 45,9 & 27,2 & 64,2 \\
\hline 2007 & 55.754 .071 & 72,4 & 56,4 & 52.363.199 & 32.562 .081 & 62,5 \\
\hline
\end{tabular}

Fonte: IBGE/PNADs-Microdados. 
As particularidades das formas de inserção ocupacional das trabalhadoras revelam também que, para o caso brasileiro, o aumento da participação no mercado de trabalho não signi cou afastamento das atividades da esfera reprodutiva. A chamada "dupla jornada de trabalho" ainda é um percalço a constrangê-las. A presença de lhos e a posição de "dona de casa" tencionam o seu ingresso no mercado de trabalho. As "tarefas do lar", menosprezadas pelas estatísticas, possuem também forte traço cultural a depender do país ${ }^{23}$. Por outro lado, se a "competitividade" das mulheres no mercado de trabalho aumenta a depender do seu nível de escolaridade, o mesmo não se pode dizer da diferenciação interna de rendimentos para um mesmo posto de trabalho, espaço de assimetria entre os sexos. Esse dado, quando tomado em sua forma bruta, ou seja, considerando-se a evolução da renda de todos os trabalhadores brasileiros, tem demonstrado crescimento paulatino. Segundo dados da Pesquisa Nacional por Amostra de Domicílios $(P N A D)^{24}$ de 2009, entre 2004 e 2009 a renda média do trabalhador cresceu $20 \%$, cujo percentual foi de $5,9 \%$ para os trabalhadores mais pobres ${ }^{25}$.

Os dados aqui utilizados sobre algumas características do mercado de trabalho brasileiro não têm a intenção de esgotar as assimetrias entre os sexos nas relações de trabalho e formas de inserção ocupacional, visam apenas pôr em destaque a limitação da ideia de que o trabalho é fonte de autonomização das mulheres. Seja pelas particularidades de setores onde a "feminização" ocorre em detrimento da naturalização de supostas qualidades femininas, como paciência, destreza, passividade etc., seja pela estrutura familiar, que limita o ingresso das mulheres no mercado de trabalho,

23 A esse respeito é possivel a rmar que as análises que referendam o trabalho enquanto lócus privilegiado de integração e o tomam como elemento primeiro para uma pretensa transformação social, ao menos em sua versão mais "ortodoxa", reforçam a primazia do trabalho produtivo nos termos marxianos. Revelando-se insensíveis ao trabalho realizado na esfera produtiva. A propósito, o ganho analítico da binaridade clássica da sociologia do trabalho ao falar em "esfera produtiva" e "esfera reprodutiva" é posto em questão, justamente por não capturar a ideia de que a "esfera reprodutiva" está integrada ao ciclo de valorização econômica, considerandose, assim, que as atividades domésticas são comercializadas como mercadorias. No entanto, Gadrey e Jany-Catrice (apud TALAHITE, 2010) veem com cautela esse entendimento na medida em que poderia - pela inclusão de tais atividades no cálculo do PIB - mercantilizar variáveis que não são econômicas, desembocando novamente no dilema da e ciência econômica como valor único, legitimando o rebaixamento das mulheres a essa escala. 
sobretudo por restringir uma ideia de autonomia que não se contém na relação de trabalho. Não se pretende a rmar que o trabalho - não somente enquanto fonte de renda, mas fonte de signi cados na vida dos indivíduos - está por completo exaurido, ocupando pouco espaço na vida dos indivíduos. Ver-se-á que o nosso propósito é armar a questão da autonomia em termos de justiça social, trata-se de um arranjo que deve ser pensado na forma de direitos, não estando restrita à mera inserção pelo trabalho. Sem a pretensão de exaurir este tema, dedicaremos a última parte desse texto ao avanço dessa ideia.

\section{A autonomia como justiça social: a inserção do princípio rawlsiano}

Nas sociedades tradicionais o peso de visões de mundo de caráter extramundano in uenciava as ações humanas revestindo-as de pretensão de validade universal; nesse contexto, argumentos a favor de princípios de autonomia, emancipação, justiça etc., tomavam como referência ideias religiosas e metafísicas de nindo o conteúdo moral das ações humanas. Acontece que a emergência de sociedades pluralistas - com o destronamento das ideias religiosas, o enfraquecimento do peso das tradições, com o papel de destaque ocupado pela ciência empírica etc. - promoveu um "deslocamento para dentro", intramundano, da fundamentação dos valores e normas que regulam a vida em sociedade (HABERMAS, 1987; GIDDENS, 1991). A con uência de reivindicações oriundas de diferentes atores sociais com os con itos potenciais que dela surgem, demanda uma forma de regulação que não recorra à violência e que esteja assentada numa ordem racional intramundana. Se isto for verdade, pensar a questão da justiça como referência para a promoção de direitos nos livra da tarefa de ter que de nir ex-ante os ns últimos da vida humana. Ao alinhavar a promoção da autonomia das mulheres à sua inserção no mercado de trabalho, incorre-se em dois problemas: primeiro - e já apontado alhures -, não problematiza o potencial emancipatório do acesso a um emprego; segundo, não leva em consideração a manutenção de formas de exploração e discriminação entre os sexos, mesmo com o ingresso das mulheres no mercado de trabalho. 
Para uma parte da teoria social, fortemente marcada pelos escritos de Marx, o sujeito da transformação social é o trabalhador, visto como agente propulsor da mudança em virtude do lugar privilegiado que a relação capital versus trabalho ocupa no interior de tais análises (LESSA, 2007; MESZÁROS, 2002). Nesse registro, a inserção de outras demandas (ecológica, de raça etc.) não se sobrepõe à primazia do trabalho. Todavia, e atentos à farta literatura que discute a questão de gênero nas relações de trabalho, nos locais de trabalho, nas formas de inserção ocupacional diferenciada entre os sexos etc. (HIRATA e KERGOAT, 2007; LOBO, 2011), a chave em que propomos pensar a questão da autonomia das mulheres de ne-se enquanto questão de justiça, não se limitando ao acesso a um emprego remunerado.

Longe daqueles que vaticinam, de maneira pura e simples, o " $\mathrm{m}$ da centralidade do trabalho", alguns dos quais citados no início deste texto, talvez possamos recuperar um elemento que havia naquelas teses: a ideia de que com a emergência dos novos movimentos sociais na década de 1960 e 1970 seria necessário repensar o papel ocupado pelo proletariado na teoria clássica. Não estamos arguindo aqui acerca da fertilidade analítica de estudos que ainda advogam um suposto papel histórico da classe operária, visto que são coerentes com aquilo que pretendem estudar do ponto de vista do referencial teórico assumido. Interessa-nos, em outro registro, pôr em destaque que: se assumirmos o "paradigma do trabalho" como vetor em que a contradição básica do capital se revela e como elemento primeiro de integração social, isto desembocará numa forma de arranjo societal que eleva as políticas de emprego e de acesso ao trabalho como fundamentais para se pensar uma sociedade justa, sem mencionar que as formas de justiça social pensadas no interior da sociedade burguesa não resolvem o âmago da questão.

Os estudos que se propõem a construir um pressuposto teórico que esteja fora do elemento trabalho, ou de uma visão da sociedade em uma perspectiva produtivista (GORZ, 2003), ampliam as possibilidades de se desvincular a ideia de autonomia da ideia de inserção pelo trabalho. O que parece estar de acordo com o que a rma Kergoat (2001), ou seja, ao questionar se o trabalho é um instrumento de libertação das mulheres, não se trata de inquirir se o trabalho pro ssional é ou não emancipador nem descrever os 
horizontes dessa emancipação; ao invés, o enfoque deve se concentrar não no trabalho em si mesmo, mas na relação particular que as mulheres desenvolvem no trabalho em razão das posições que elas ocupam na divisão sexual do trabalho. Para Kergoat (2001), a necessidade de considerar conjuntamente o trabalho produtivo e reprodutivo para compreender a organização do trabalho conduz os pesquisadores a questionar a estrutura do mercado de trabalho, a relação no emprego, no salário, no tempo de trabalho etc., e é isto que se revela teoricamente subversivo ${ }^{26}$.

Não se trata de desenvolver o argumento de um novo sujeito social "sem face" 27 , mas de propor a ideia de que a autonomia das mulheres, e suas reivindicações, devem ser formuladas na forma de direitos. É aqui que posicionamos a concepção de justiça social desenvolvida por John Rawls. Embora Rawls (2008) não esteja interessado em fornecer um modelo ideal de sociedade, ele fornece elementos para se pensar o estabelecimento de uma sociedade democrática frente ao pluralismo de valores. Para Rawls (2008) o foco da justiça deve ser o que ele chama de "estrutura básica da sociedade", ou seja, é sobre esta estrutura que se aplicam os princípios de justiça social. Assim, "a justiça de um arranjo social depende, em essência, de como se atribuem os direitos e deveres fundamentais e também das oportunidades econômicas e das condições sociais dos diversos setores da sociedade" (RAWLS, 2008: p. 9). O modelo rawlsiano parte de uma situação hipotética em que os homens, estando em uma situação de igualdade real, seriam convidados a regular suas reivindicações mútuas, sobre o que é justo e injusto e assim por diante. Esse recurso permite visualizar uma posição em que os indivíduos, sem a in uência do seu lugar na sociedade, escolheriam os princípios de justiça "sob um véu de ignorância". Rawls é ciente de que os indivíduos quando nascem já encontram uma dada posição na sociedade que repercute em suas escolhas e perspectivas de vida, no entanto,

26 Em uma formulação de maior fôlego, Kergoat (2010) desenvolve a tese da consubstancialidade das relações sociais. Em face do paradoxo de que a participação da mulher no mercado de trabalho aumenta e as segmentações entre empregos masculinos e femininos permanecem, faz-se mister uma nova maneira de se pensar a dinâmica das relações sociais de sexo. Donde o recurso à ideia de que relações sociais são consubstanciais, no sentido de que "a diferenciação dos tipos de relações sociais é uma operação por vezes necessária à sociologia, mas que é analítica e não pode ser aplicada inadvertidamente à análise das práticas sociais concretas" (KERGOAT, 2010, p. 94).

27 No sentido que Horkheimer compreende como sendo o sujeito da Teoria Crítica. 
entende-se que as partes, em situação de equidade e descompromissadas com relação aos seus interesses imediatos, poderiam acordar sobre os princípios de justiça que irão regular as interações sociais. Este modelo não almeja o estabelecimento de uma igualdade absoluta em termos de igualdade socioeconômica, ele comporta certo grau de desigualdades sociais e econômicas desde que resultem de vantagens recompensadoras para todos e, em especial, para os menos favorecidos da sociedade (RAWLS, 2008).

Ao longo de sua obra, Rawls (2008) desenvolve com maior precisão a sua concepção de justiça social. Para o nosso interesse, ela se torna um importante recurso analítico na medida em que nos permite avançar numa concepção de justiça social capaz de comportar as reivindicações por autonomia de nindo-a na linguagem dos direitos.

Desatrelando-a, assim como fez Silva (2008), da noção de cidadania, da ligação com o trabalho. Se estivermos certos, uma vez que os achados de pesquisa revelam a manutenção da divisão sexual do trabalho, as segmentações horizontais e verticais nas relações de trabalho nas quais a clivagem de gênero - mas não só ela - é determinante, a essencialização de relações sociais que atuam em desfavor das mulheres etc., pautar as demandas oriundas da questão de gênero na forma como sugerimos aqui permite um ganho analítico considerável. Na medida em que não mais se trata de pensar uma forma "autêntica" de autonomia para as mulheres - a exemplo do que vimos aqui com as políticas que promovem a inserção pelo trabalho -, ou mesmo de reivindicar uma pretensa "tomada de consciência" das mulheres da dominação masculina ${ }^{28}$, essa abordagem nos permitiria "armar" questões de uma maneira diferente. Avancemos um pouco mais neste argumento.

Cônscios de que a passagem de diversas demandas para o plano dos direitos não é tarefa simples, por envolver um jogo de forças dos que pleiteiam a validade do seu argumento (HABERMAS, 1987) e de que, superada esta etapa (seja na forma da positivação em lei ou na forma de política pública), ainda falta a sua efetividade, ou seja, o seu cumprimento. Mesmo

28 A associação com o famoso livro homônimo de Pierre Bourdieu é casual, ainda assim, no sentido que estamos argumentando, a nossa hipótese talvez nos permita sair da situação "claustrofóbica" na qual desemboca a sua análise sobre a situação de dominação a que estão sujeitos os dominados. Deixamos essa questão em aberto. 
assim, somente nesta dimensão de "negociação" de interesses, de princípios de justiça, de de nição de um parâmetro mínimo de justiça é que pode ser assentada a pauta de reivindicações por autonomia (mas não só isso) das mulheres. É escusado dizer que estamos falando aqui de arranjos de sociedades democráticas liberais.

É preciso também ressaltar que não estamos ofertando uma forma acabada, ou um modelo ideal de sociedade; ao contrário, desenvolve-se aqui uma ideia ainda em elaboração, um esforço na tentativa de equacionar um determinado problema (a autonomia das mulheres associada à inserção pelo trabalho) com uma possível forma de interpretação.

Como vimos, não é o trabalho por si só que vai garantir a autonomia ou a emancipação das mulheres, mas a forma com que, pela sua posição na divisão sexual do trabalho, as mulheres podem desestabilizar a relação de forças entre as classes do sexo (KERGOAT, 2010). Para tanto, as reivindicações de gênero inscrevem-se como questão de justiça ${ }^{29}$.

Segundo Rawls (2008), existem dois princípios básicos de justiça. O primeiro está ligado à noção de que cada pessoa deve ter um direito igual ao sistema mais extenso de iguais liberdades fundamentais, compatível com um sistema similar de liberdades para as outras pessoas, ou seja, é o marco fundamental da igualdade jurídica. O segundo princípio sustenta que as desigualdades sociais e econômicas possam estar dispostas de tal modo que se estabeleçam em benefício de todos, assim como estejam associadas a cargos e posições acessíveis a todos (RAWLS, 2008). A ideia de "benefício de todos" refere-se à superação de desigualdades intransponíveis, aquelas associadas a posições estabelecidas e inalteradas. Para Rawls (2008), o primeiro princípio tem prioridade sobre o segundo, ou seja, não é possível justi car ou compensar por meio de vantagens sociais e econômicas a supressão das iguais liberdades fundamentais. Isto demonstra a preocupação com o aparecimento de regimes autoritários que em nome de uma suposta

29 Essa ideia não signi ca a exclusão da necessidade de transformação de elementos que estão no seio da cultura, a exemplo de práticas relacionadas à divisão das tarefas no lar, comportamentais, simbólicas, nem sempre claras e passíveis de transformação pela garantia de direitos. No entanto, seguindo a pista deixada por Goffman (1977), não são as consequências sociais de diferenças sexuais inatas que devem ser explicadas, mas o modo pelo qual tais diferenças foram (ou são) sugeridas como uma garantia para nossos arranjos sociais, e, sobretudo, o modo pelo qual o trabalho institucional da sociedade assegurou que esta proposição se tornasse plausível, razoável. 
igualdade da maioria, suprimiram liberdades fundamentais dos indivíduos. Assim, possibilitar a inserção das mulheres no mercado de trabalho não caminha na contramão da concepção de justiça social desenvolvida por Rawls, até porque ela operaria em "benefício de todos". Todavia, esta medida pode não ter a e cácia almejada para a superação das assimetrias entre os sexos, reforçando a tese de que o campo de disputa para a superação dessas desigualdades está no argumento rawlsiano da "negociação" de princípios de justiça.

No bojo dessa discussão não resistimos à ideia de "paridade de participação" desenvolvida por Fraser (2000). Por meio dela a autora desenvolve uma crítica à limitação da noção de "reconhecimento" desenvolvida por Honneth (2003). Segundo Fraser, os movimentos que expressam suas reivindicações nessa gramática - na forma do reconhecimento - incorrem em dois perigos: a) o "problema do deslocamento", no qual os con itos de redistribuição são subsumidos ou mesmo marginalizados; b) e o "problema da rei cação", em que o reconhecimento se transforma na política da identidade e acaba por promover não a aceitação da diferença, mas uma cultura de autoa rmação de grupos que rei cam identidades. Para Fraser (2000), ainda que a política da identidade contenha algo de positivo, na medida em que oferta algum conforto psicológico para problemas como o sexismo, racismo, imperialismo cultural etc., ela acarreta problemas de ordem teórica e política. Isto se deve, ainda segundo a autora, por não tratar das desigualdades de outra ordem, principalmente a econômica, ou por considerá-las epifenômenos de problemas cuja raiz é de ordem cultural.

A esse respeito, Fraser (2000) re na o seu argumento não caindo no lugar-comum de a rmar uma simples sobreposição de uma forma de abordagem por outra. Para ela, não seria possível pensar a questão do "não-reconhecimento" abstraindo-se de sua matriz institucional e também do seu entrelaçamento com questões de ordem econômica. No primeiro aspecto, signi ca dizer que as desigualdades também estão inseridas na forma de leis, de normas, de políticas públicas etc., ou seja, no plano institucional. No segundo aspecto, não seria possível superar algumas formas de desigualdades apenas no "plano da cultura", sem tratar de questões referentes à distribuição da riqueza e do bem-estar. Uma forma de equacionar este 
problema estaria em tratar a questão do reconhecimento como uma questão de status social (FRASER, 2000). Não sendo apenas uma questão cultural, o não-reconhecimento é uma forma de subordinação institucionalizada, portanto, uma violação da justiça. Aqui surge o elemento que queremos pôr em evidência na contribuição dessa autora. Uma vez que o problema é menos o do reconhecimento de uma identidade especí ca de grupo e mais o do desenvolvimento do status do indivíduo enquanto membro completo da sociedade, apto a participar em condições de paridade com os demais,

Reparar o não-reconhecimento signi ca agora mudar as instituições sociais ou, mais precisamente, mudar os valores que regulam a interação e que impedem a paridade de participação em todos os espaços institucionais relevantes. Como isso deve ser feito exatamente em cada caso depende da forma em que o não-reconhecimento está institucionalizado. Formas jurídicas exigem uma mudança legal, formas políticas arraigadas exigem mudança política, formas associativas requerem mudança associativa, e assim por diante (FRASER, 2000, p. $115)^{30}$.

Assim formulado, é possível propor uma aproximação entre a ideia de "paridade de participação" (FRASER, 2000) com o argumento da "justiça como equidade" (RAWLS, 2001). Ainda que por caminhos diversos, ambos estão pensando nas condições de elegibilidade dos indivíduos enquanto sujeitos capazes de reivindicar a validade do seu argumento. Por outras palavras, não se trata de a rmar que identidades de classe, de gênero, gays ou lésbicas, étnicas, de proveniência etc., não devam ser observadas e reconhecidas, sobretudo quando não são reconhecidas na diferença; trata-se, na verdade, de reconhecer os reivindicantes enquanto sujeitos aptos a "negociar" as suas demandas de justiça.

É justamente o argumento que nos propomos a desenvolver nesse texto ao situar as reivindicações por "autonomia" das mulheres ou por "reconhecimento" - para usar o termo de Honneth - em termos de justiça social. Vejamos alguns casos que possam nos ajudar nessa re exão.

No Brasil, a promulgação da Lei n’11.340 (Lei "Maria da Penha”), em

30 No original: "Redressing misrecognition now means changing social institutions or, more speci cally, changing the interaction-regulating values that impede parity of participation at all relevant institutional sites. Exactly how this should be done depends in each case on the mode in which misrecognition is institutionalized. Juridi ed forms require legal change, policy-entrenched forms require policy change, associational forms require associational change, and so on". 
2006, tem ajudado a reduzir a violência contra as mulheres. Uma pesquisa realizada pelo IBOPE e pelo Instituto Avon - disponibilizada no site da Secretaria de Política para as Mulheres ${ }^{31}$ - revela, entre outras coisas, o aumento da visibilidade da violência contra a mulher. A pesquisa fez uma segmentação por região do Brasil com destaque especial para a região Nordeste, conforme dados da Tabela 2.

Tabela 2 - resposta à pergunta: "você conhece alguma mulher que sofre ou já sofreu agressões..."

\begin{tabular}{|l|c|c|c|c|}
\hline $\begin{array}{l}\text { "Vocé conhece alguma } \\
\text { mulher que sofre ou já } \\
\text { sofreu agressóes..." }\end{array}$ & \multicolumn{2}{|c|}{$\begin{array}{c}\text { Conhece } \\
\text { (\%) }\end{array}$} & \multicolumn{2}{c|}{$\begin{array}{c}\text { Não conhece } \\
\text { (\%) }\end{array}$} \\
\hline Base: Amostra (2002) & 2006 & 2009 & 2006 & 2009 \\
\hline Norte/ C. Oeste & 51 & 55 & 49 & 45 \\
\hline Nordeste & 6 & 53 & 47 & 40 \\
\hline Sudeste & 49 & 54 & 51 & 46 \\
\hline Sul & 51 & 53 & 49 & 47 \\
\hline
\end{tabular}

Fonte: Pesquisa IBOPE / Instituto AVON 2009.

O acesso à informação, principalmente o aumento do conhecimento da Lei Maria da Penha, o recurso das Delegacias da Mulher, o debate público e o ativismo das mulheres - como a própria pesquisa sugere - contribuíram para esse índice. O conhecimento do agressor, dos locais onde ocorrem as agressões e dos recursos disponíveis para punir o agressor, ainda que não garantam a efetiva medida de segurança, ao menos constituem um avanço em termos da superação desta manifestação de violência. Vale ressaltar que dos 5.565 municípios brasileiros, apenas 274 contam com atendimento judicial especializado para este tipo de violência ${ }^{32}$.

No tocante às informações sobre o acesso ao trabalho para as muIheres, o próprio IBGE aponta que, no Brasil, desde a década de 1980 tem crescido a participação das mulheres no mercado de trabalho ${ }^{33}$, superando outros países da América do Sul e equiparando-se aos países desenvolvidos, como sugere o Grá co 1.

31 Disponível em: http://www.sepm.gov.br/nucleo/dados/pesquisa-avon-violencia-domestica-2009.pdf

32 Fonte: IBGE/SIS 2010.

33 Dados da Pesquisa Nacional por Amostra de Domicílios - PNAD 2009. 
Grá co 1 - taxa de atividade das mulheres de 15 anos ou mais de idade, por grupos de idade, segundo os países selecionados - 2006

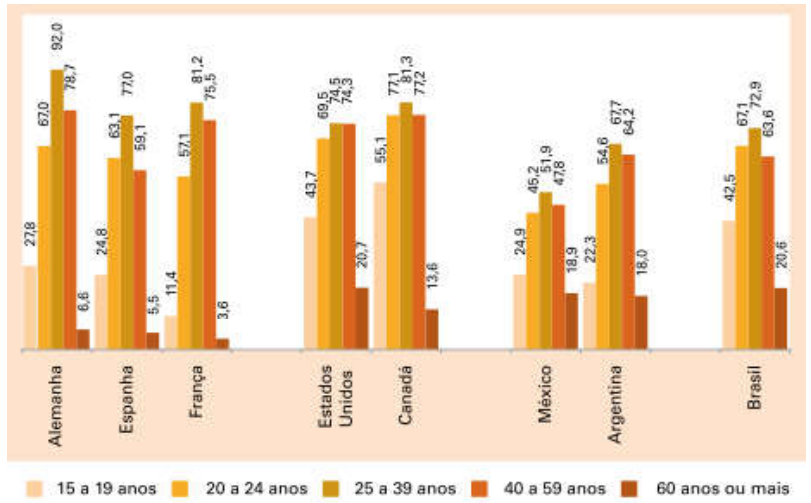

Fonte: IBGE/SIS 2009.

Já comentamos anteriormente a crítica feita por Talahite (2010) a este tipo de indicador, pois não revela a qualidade dos empregos e não leva em consideração o trabalho doméstico. Sobre isso, dois indicadores da pesquisa do IBGE são instrutivos, a saber, a distribuição por sexo segundo a posição na ocupação (Grá co 2) e o rendimento médio do trabalho das mulheres versus o dos homens (Grá co 3 ).

Grá co 2 - Proporção das pessoas ocupadas de 10 anos ou mais de idade, por sexo, segundo a posição na ocupação. Brasil - 2008

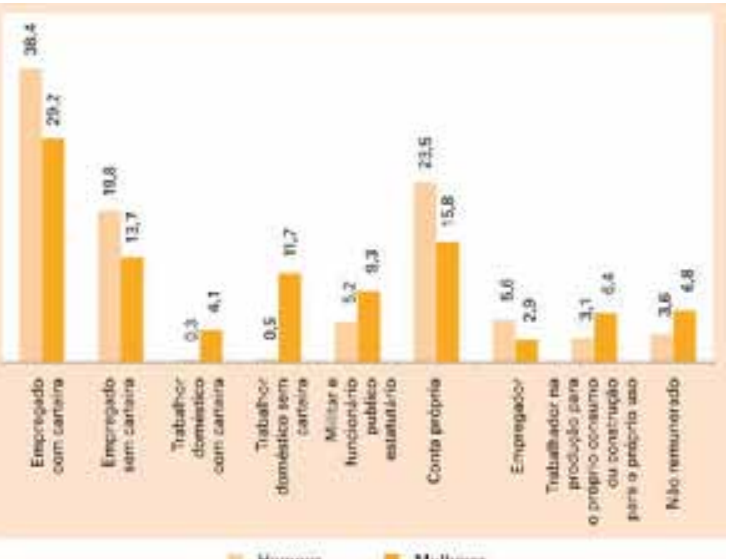

Fonte: IBGE/SIS 2009. 


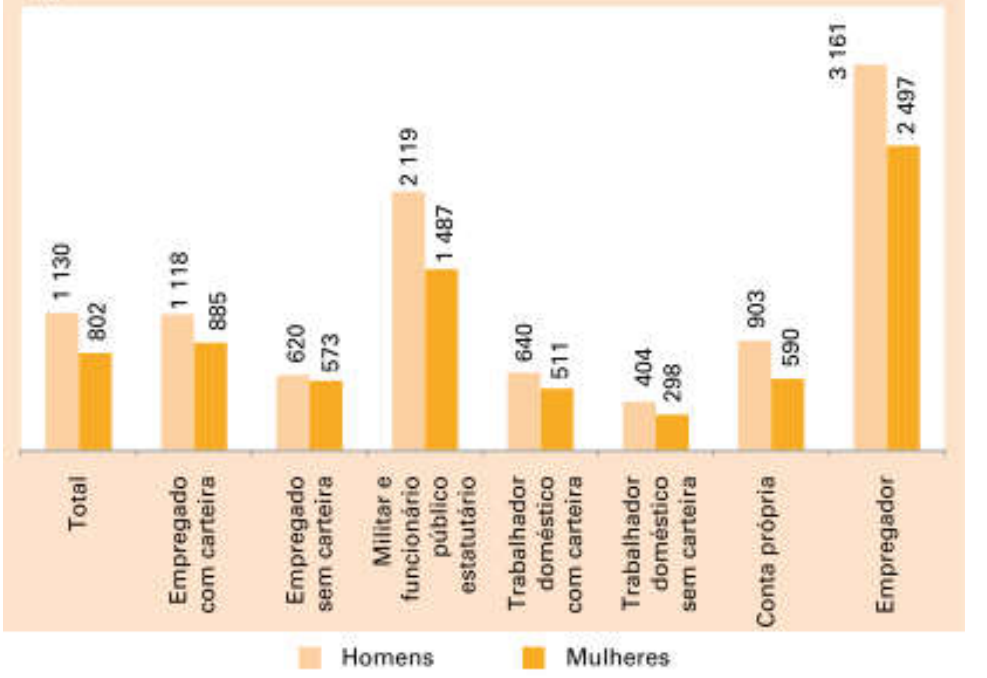

Fonte: IBGE/SIS 2009.

Constata-se no Grá co 2 a forte presença das mulheres no trabalho doméstico (com ou sem carteira), o que revela uma in exão de gênero. $O$ mesmo vale para o Grá co 3 , rati cando a atualidade da tese da assimetria de rendimentos entre homens e mulheres. Cientes de que a análise desses dados requer uma leitura mais cuidadosa, eles aparecem aqui apenas com o intuito de ilustrar, no caso do Brasil, que as disparidades ainda existem e que elas conferem robustez às reivindicações dos movimentos feministas.

Por outro lado, e alinhavando mais uma vez ao argumento aqui desenvolvido, tais demandas ganham força à medida que são pautadas em termos de justiça social, seja na forma de leis, normas ou políticas públicas que visam à superação dessas disparidades, concebendo - mas sobretudo promovendo -, assim como sugerem Fraser (2000) e Rawls (1998), a capacidade plena desses atores de reivindicar a demanda de justiça requerida. Ainda a esse respeito, a ideia de justiça social em Rawls (1998) é sensível à incorporação de mecanismos da justiça distributiva, à medida que as desigualdades econômicas podem limitar a possibilidade da equiparação no plano do "status de reconhecimento" (FRASER, 2000), ou da cidadania (SILVA, 2008). 
Não se pretende a rmar que a emancipação ou autonomia das mulheres resume-se a uma questão de normatividade, ao contrário, discute-se aqui um caminho analítico para interpretar aquelas reivindicações e, com menor ênfase, alguns impasses políticos dos casos aqui citados.

Há ainda que se ressaltar que o argumento rawlsiano de justiça social não repousa confortavelmente no interior da teoria política normativa. Ele se situa em uma zona de confronto com outras interpretações acerca das possibilidades de se pensar o consenso em sociedades pluralistas, ou melhor, a função legitimadora do uso público da razão. Neste aspecto, uma crítica pertinente interposta a Rawls provém de Jurgen Habermas. Instigado pelo mesmo problema, Habermas (1998) não questiona o projeto desenvolvido por Rawls como um todo, ao invés, ele aponta algumas limitações no interior de sua teoria. A primeira delas se refere à questão da "posição original".

Habermas (1998) nutre algumas dúvidas sobre se o seu desenho é capaz de assegurar o ponto de vista da imparcialidade do julgamento dos princípios deontológicos de justiça. Isto porque, como vimos alhures, Rawls (1998) pressupõe que as escolhas racionais dos atores nesta situação estariam sujeitas a constrangimentos especí cos que garantiriam a imparcialidade das questões práticas. Novamente o recurso ao "véu de ignorância" como uma ideia na qual os membros, "privados" da informação sobre os interesses dos outros participantes, escolheriam os princípios de justiça guiados apenas pelo autointeresse. Rawls (1998) entende que, ao possuírem concepções intuitivas de justiça, os participantes saberiam escolher o que é igualmente bom para todos. Por outras palavras, no argumento rawlsiano, as concepções particulares dos atores não os impedem de pensar um arranjo "bom para todos", há uma aposta no ideal de "civilidade" que motiva a busca pelo consenso.

Por seu turno, Habermas (1998) descon a de que apenas o autointeresse dos atores possa regular as escolhas. Além disso, a falta de informações acerca dos outros participantes como condição de acesso à "posição original" não parece ser um mecanismo e ciente para o caso das sociedades pluralistas. A crítica habermasiana somente pode ser compreendida quando nos voltamos para a maneira com que ele procura equacionar a pluralidade dos interesses existentes com um ideal de justiça comum. Neste 
sentido, no seu entender, não há nenhuma razão para se temer o crescimento do pluralismo cultural nas democracias constitucionais modernas. No entanto, Habermas (1998), ao contrário de Rawls (1998), aposta na ideia de que a práxis intersubjetiva da argumentação é que oferta a melhor condição para o estabelecimento do consenso. Ao invés de neutralizar a multiplicidade de perspectivas particulares logo no início - como pressupõe o desenho da "posição original" - é justamente o recurso a elas que permite aos atores buscar a validade do seu argumento em condições de entendimento linguisticamente estruturado.

A base sobre a qual repousa o mecanismo de deliberação proposto por Habermas (1987) encontra fundamentação na ideia de que os indivíduos compartilham, em algum grau, de processos comunicativos mediados linguisticamente ${ }^{34}$. Donde,

Se quisermos garantir que nenhuma discrepância surja, devemos conceber a posição original já com o conhecimento, e até mesmo a previsão, de todos os conteúdos normativos que poderiam potencialmente nutrir a auto-compreensão partilhada dos cidadãos livres e iguais no futuro (HABERMAS, 1998, p. $58)^{35}$.

Depreende-se então que, embora Rawls e Habermas divirjam acerca dos mecanismos que propiciariam um possível consenso sobre princípios de justiça, em ambos é possível destacar o investimento na negociação das demandas dos diferentes atores que, não representando mais a imposição de um ethos moral comum, permita estabelecer na forma de direitos as garantias para a livre manifestação dos indivíduos. É aqui que situamos as reivindicações por autonomia das mulheres. Elas se inserem menos na rea rmação de uma identidade putativa, rei cada sobre as mulheres (que as políticas de promoção do emprego feminino acabam por reforçar ao vincular autonomia ao trabalho), e mais na promoção de suas demandas enquanto

34 Para Habermas (1987), as normas que orientam as práticas deliberativas devem garantir que: I)

ninguém que pode contribuir deve ser excluído a priori, II) os participantes devem ter igual oportunidade de fazer suas contribuições, III) não deve haver nenhum constrangimento de nenhuma ordem. tentially nourish the shared self-understanding of free and equal citizens in the future". 
questão de justiça social. Pelo reconhecimento de que elas são sujeitos partícipes no estabelecimento de princípios de justiça consensualmente negociados.

\section{À guisa de conclusão}

Quando se toma o acesso a um emprego remunerado como elemento de autonomia e de superação das assimetrias entre os sexos, esquece-se muitas vezes de que a própria inserção das mulheres no mercado de trabalho se dá por caminhos obscuros, que geram desigualdades especí cas. Os estudos sobre globalização, mercado de trabalho, divisão sexual do trabalho ou, ainda, sobre as condições especí cas em que ocorre o trabalho feminino, já citados neste texto, revelam as disparidades presentes em cada contexto. Os indicadores usados por muitas agências de desenvolvimento, por si sós, como foi mostrado, não nos dão a clara percepção do lugar das mulheres no trabalho. Dessa forma, a vinculação do acesso ao trabalho a uma pretensa emancipação ou autonomia das mulheres não supera as desigualdades entre os sexos.

Por outro lado, isto não signi ca dizer que o trabalho, e o espaço de sociabilidade que ele representa, deixou de ser um lócus privilegiado de questionamento e confronto com tais desigualdades, como sustentam algumas das posições aqui elencadas. Para esta corrente interpretativa, falar em trabalho como elemento emancipador contradiz o que eles a rmam ser a realidade pós-reestruturação produtiva. Na medida em que são as esferas fora do trabalho - como a família ou a comunidade - que seriam espaços de realização e potencializadores de transformação social, a esfera do trabalho não representaria mais um espaço privilegiado de confronto com ideologias dominantes. A esse respeito, incorporamos o argumento de Kergoat (2001), mostrando que tal separação não traz nenhuma vantagem analítica, além de dissociar problemas que possuem uma imbricação particular, especialmente sobre a questão de gênero. O potencial subversivo do gênero não se revelaria apenas na sua dimensão individual, portanto, a sociabilidade proporcionada pela relação de trabalho é que permite o questionamento para além daquela dimensão. Também procuramos nos afastar de teorias que pleiteiam primazia analítica de determinados fenômenos, seja pelo viés 
"culturalista" seja pelo "economicista". Ao contrário, apostamos em uma hipótese e procuramos desenvolver a forma pela qual armamos o nosso argumento.

A realidade brasileira é sugestiva e nos fornece bons elementos para se pensar questões de gênero - mas não só ela - nos termos aqui sugeridos. O ativismo político dos movimentos sociais feministas, dos sindicatos, do movimento LGBT, entre outros, tem conseguido avançar na conquista de suas reivindicações, ainda que retrocessos também sejam visíveis. $\mathrm{Na}$ hipótese aqui sugerida, a inserção do princípio rawlsiano de justiça revela-se como um caminho fértil para equacionar as demandas desses agentes à medida que, para satisfazer as exigências da justiça, não é necessário levar em conta a in ndável variedade das posições relativas das pessoas, mas a forma como elas são negociadas, donde resulta o que é justo ou injusto.

Ao $m$ e ao cabo, questões como o reconhecimento da união de casais do mesmo sexo, da legislação sobre assédio moral, das delegacias especializadas de crimes contra a mulher, a legalização do aborto etc., só podem ser discutidas quando se promove a "paridade de participação" dos reivindicantes. Se esta condição não esgota outras formas de discriminação, conquanto elas existam, o argumento aqui explorado permite arejar o campo epistêmico a partir do qual novas questões podem ser formuladas.

\section{Referências}

ABRAMO, Lais Wendel. O Resgate da Dignidade: greve metalúrgica e subjetividade operária. Campinas: Editora da Unicamp, 2000.

AGIER, Michel; CASTRO, Nadya A.; GUIMARÃES, A. S. Imagens e Identidades do Trabalho. São Paulo: HUCITEC, 1995.

ALVES, Giovanni. O Novo (e Precário) Mundo do Trabalho: reestruturação produtiva e crise do sindicalismo. São Paulo: Boitempo, 2000.

ANTUNES, Ricardo. Os Sentidos do Trabalho: ensaio sobre a a rmação e a negação do trabalho. 2. ed. São Paulo: Boitempo, 1999.

BECK, Ulrich. The Brave New World of Work. Malden: Blackwell Publishers, 2000. 
BALES, Kevin. Disposable People: new slavery in the global economy. Princeton: Princeton University, 2004.

BELL, D. 0 advento da sociedade pós-industrial: uma tentativa de previsão social. São Paulo: Cultrix, 1977.

BOURDIEU, Pierre. A Dominação Masculina. Rio de Janeiro: Bertrand Brasil, 2002.

CARDOSO, Adalberto Moreira. Trabalhar, verbo transitivo: destinos pro ssionais dos deserdados da indústria automobilística. Rio de Janeiro: editora FGV, 2000.

CASTEL, Robert. As Metamorfoses da Questão Social: uma crônica do salário. Petrópolis/RJ: Vozes, 1998.

COSTA, A. et al. Mercado de Trabalho e Gênero: comparações internacionais. Rio de Janeiro: Ed. FGV, 2008.

DAL ROSSO, Sadi. Mais trabalho! A intensi cação do labor na sociedade contemporânea. São Paulo: Boitempo, 2008.

DAU, Denise Motta; CONCEIÇÃO, Jefferson José da; RODRIGUES, Iram Jacome. Terceirização no Brasil: Do Discurso da Inovação: a precarização do trabalho. São Paulo: Annablume, 2009.

DEDECCA, Cláudio. Racionalização Econômica e Trabalho no Capitalismo. Campinas-SP: Teses - Fecamp, 1999.

DE MASI, Domenico. O Futuro do Trabalho: fadiga e ócio na sociedade pós-industrial. Rio de Janeiro: José Olympio, 2003.

EHRENREICH, Bárbara. Desemprego de Colarinho-Branco. Rio de Janeiro: Record, 2006.

FRASER, Nancy. Rethinking Recognition. New Left Review, 3, Jun., p. 107120. 2000.

GIDDENS, Anthony. As Consequências da Modernidade. São Paulo: Unesp, 1991.

GUIMARÃES, Antônio Sérgio A. Um Sonho de Classe. São Paulo: HUCITEC, 1998.

GUIMARÃES, Nadya Araujo. Caminhos Cruzados: estratégias de empresas e trajetórias de trabalhadores. São Paulo: Ed. 34, 2004.

GUIMARÃES, Nadya Araujo et al. Mercados de Trabalho e Oportunidades: reestruturação econômica, mudança ocupacional e desigualdade na Inglaterra e no Brasil. Rio de Janeiro: FAPERJ / FGV, 2008.

GUIMARÃES, Nadya Araujo. Trabalho Flexível, Empregos Precários? Uma 
comparação Brasil, França, Japão. In: GUIMARÃES, Nadya Araujo; HIRATA, Helena; SUGITA, Kurumi (org.). Trabalho Flexível, Empregos Precários? Uma comparação Brasil, França, Japão. São Paulo: EDUSP, 2009.

GOFFMAN, Erving. The arrangement between the sexes. Theory and Society, v. 4, n. 3, 1977.

GORZ, Andre. Adeus ao Proletariado: para além do socialismo. Rio de Janeiro: Forense Universitária, 1982.

GORZ, Andre. Metamorfoses do Trabalho. São Paulo: Annablume, 2003. HABERMAS, Jürgen. Teoría de la Acción Comunicativa. Madrid, Taurus, 1987.

GORZ, Andre. Legitimation Crisis. Boston: Beacon Press, 1975.

GORZ, Andre. The Inclusion of the Other: studies in political theory. Cambridge: The MIT Press, 1998.

HARDING, Sandra. Whose Science? Whose Knowledge? Thinking From Women's Lives. New York: Cornell University Press. 1991.

HARVEY, David. Condição Pós-Moderna: uma pesquisa sobre as origens da mudança cultural. 3. ed. São Paulo: Loyola, 1993.

HIRATA, Helena; KERGOAT, Danièle. Novas Con gurações da Divisão Sexual do Trabalho. Cadernos de Pesquisa, v. 37, n. 132, p. 595-609, 2007. HONNETH, Axel. Luta Por Reconhecimento: a gramática moral dos con itos sociais. São Paulo: Editora 34, 2003.

HUWS, Ursula. The Making of a Cybertariat. New York: New York University, 2004.

INSTITUTO BRASILEIRO DE GEOGRAFIA E ESTATÍSTICA. Pesquisa Nacional de Amostra por domicílio. Disponível em: http://www.ibge.gov. br/home/estatistica/populacao/trabalhoerendimento/pnad2009/. Acesso em: 15de fevereiro de 2011.

INSTITUTO BRASILEIRO DE OPINIÃO PÚBLICA E ESTATÍSTICA; INSTITUTO AVON. Percepções e reações da sociedade sobre a violência contra a mulher: 2009. Disponível em: http://www.spm.gov.br/ subsecretaria-de-enfrentamento-a-violencia-contra-as-mulheres/lei-mariada-penha/2009-pesquisa-ibope.avon-violencia-domestica.pdf Acesso em: 15 de fevereiro de 2011.

KERGOAT, Danièle. Le rapport social de sexe. De la reproduction des rapports sociaux à leur subversion. Actuel Marx, n. 30, p. 85-100, 2001.

KERGOAT, Danièle. Dinâmica e Consubstancialidade das Relações Sociais. 
Novos Estudos Cebrap, São Paulo, n. 86, p. 93-103. 2010.

LAZZARATO, Maurizio; NEGRI, Antonio. Trabalho Imaterial: formas de vida e produção de subjetividade. Rio de Janeiro: DP\&A, 2001.

LEITE, Márcia de Paula; GITAHY, Leda. Novas Tramas Produtivas. São Paulo: SENAC, 2005.

LESSA, Sérgio. Trabalho e Proletariado no Capitalismo Contemporâneo. São Paulo: Cortez, 2007.

LIMA, Jacob Carlos. Ligações Perigosas: trabalho exível e trabalho associado. São Paulo: Annablume, 2007.

LOBO, Elisabeth Souza. A Classe Operária Tem Dois Sexos: trabalho, dominação e resistência. São Paulo: Perseu Abramo, 2011.

LOJKINE, Jean. A Revolução Informacional. São Paulo, Cortez, 1995.

MÉSZAROS, Istivan. Para Além do Capital. São Paulo: Boitempo, 2009.

MOLINIER, Pascale. Adimensão do cuidar no trabalho hospitalar: abordagem psicodinâmica do trabalho de enfermagem e dos serviços de manutenção. Revista brasileira de Saúde Ocupacional, v. 33, n. 118, p. 6-16, 2008.

OFFE, Claus. Trabalho como Categoria Sociológica Fundamental? In: OFFE, Claus. Trabalho \& Sociedade: problemas estruturais e perspectivas para o futuro da sociedade do trabalho. Rio de Janeiro: Tempo Universitário, 1989.

PIORE, J. Piore. SABEL, Charles F. The Second Industrial divide: possibilities for prosperity. New York, Basic Book, 1984.

POCHMANN, Márcio. O Emprego no Desenvolvimento da Nação. São Paulo: Boitempo, 2008.

POCHMANN, Márcio. Trabalho sob Fogo Cruzado. São Paulo: Contexto, 1999.

POCHMANN, Márcio. O Emprego na Globalização: a nova divisão internacional do trabalho. São Paulo: Boitempo, 2001.

RAMALHO, José Ricardo; SANTANA, Marco Aurélio. Além da Fábrica: Trabalhadores, sindicatos e a nova questão social. São Paulo: Boitempo, 2003.

RAMOS, Lauro. Desempenho Recente do Mercado de Trabalho Brasileiro: 1992-2005. Revista de Economia Política, São Paulo, v. 29, n. 4, p. 406420, out./dez. 2009.

RAWLS, John. Uma Teoria da Justiça. São Paulo: Martins Fontes, 2008.

RIFKIN, Jeremy. End of Work: The Decline Of The Global Labor Force And 
The Dawn Of The Post Market Era. New York: Putnam, 2004.

SCHAFF, Adam. A Sociedade Informática. São Paulo: UNESP, 1990.

SCOTT, Joan. Gênero: uma categoria útil para a análise histórica. Educação e Realidade. Porto Alegre, v. 6, n. 2, jul/dez 1990.

SASSEN, Saskia. Sociologia da Globalização. Porto Alegre: ARTMED, 2010.

SEGNINI, Liliana. Mulheres no Trabalho Bancário. São Paulo: EDUSP, 1998.

SILVA, Josué Pereira da. Trabalho, Cidadania e Reconhecimento. São Paulo: Annablume, 2008.

TALAHITE, Fatiha. Genre, marché du travail et mondialisation. In: FALQUET, Jules et al. Le Sexe de la Mondialization: genre, classe, race et nouvelle division du travail. Paris: Le Presses de Science Po, 2010.

TEIGER, Catherine; DANIELLOU, François. Organisation du Travail Santé. In: DEJOURS, C. (dir.). Plaisir et souffrance dans le travail. Paris: Ed. Psy. T. A. 1988. Tome 1, p. 77-78. 